\title{
THERAPEUTIC IMPORTANCE OF OLDER GENERATION ANTIBIOTICS ON GRAM NEGATIVE ISOLATES
}

\author{
B. Lakshmi ${ }^{1}$, M. Swarajya Lakshmi², Rohini ${ }^{3}$
}

${ }^{1}$ Associate Professor, Department of Microbiology, MNR Medical College and Hospital, Fasalwadi, Sangareddy, Telangana State. ${ }^{2}$ Associate Professor, Department of Microbiology, Maheshwara Medical College, Isnapur, Patancheru, Medak, Telangana.

${ }^{3}$ Lab Technician, Department of Microbiology, MNR Medical College.

\begin{abstract}
Drug resistance is a serious medical problem. Indiscriminate use of antibiotics has led to a state where multi-drug resistant bacteria have become increasingly prevalent. Therefore regular surveillance of important pathogens and their resistant pattern is mandatory.
\end{abstract}

AIM

To find out prevalence of organisms causing infection and their sensitivity pattern.

\section{MATERIAL AND METHODS}

676 clinical samples were screened, among which 156 Gram Negative (GN) Isolates were processed for their antibiotic sensitivity profile against 12 different antibiotics.

\section{RESULTS}

Escherichia coli is the most common isolate of 156 gram negative isolates. Among all antibiotics, Ampicillin is least sensitive (22\%). Antibiotics with good sensitivity are Imipenem, Meropenem (100\%), Levofloxacin 94\%, Amikacin 89\%, Ciprofloxacin 79\%, Gentamicin $77 \%$. Pseudomonas is $100 \%$ sensitive to Amikacin.

\section{CONCLUSION}

Antibiotic resistance in our area is still moderate. It is essential to test for older generation antibiotics before deciding on higher antibiotics for treatment, which will have a tremendous impact on the treatment as well as cost effectiveness. Regular surveillance helps in implementing better therapeutic strategies.

\section{KEYWORDS}

Antibiogram, Gram Negative Isolates, Imipenem, Multi-Drug Resistance, Older Generation Antibiotics.

HOW TO CITE THIS ARTICLE: Lakshmi B, Lakshmi MS, Rohini. "Therapeutic Importance of Older Generation Antibiotics on Gram Negative Isolates." Journal of Evolution of Medical and Dental Sciences 2015; Vol. 4, Issue 104, December 28; Page: 16965-16968, DOI: $10.14260 /$ jemds/2015/2560

\section{INTRODUCTION}

Microbiological infection plays a vital role in determining the outcome as well as cost and duration of hospital stay for admitted patients.[1] Gram negative infections were responsible for more severe infections and case fatality. Severity of the cases increased by drug-resistant pathogens in hospitalized patients with serious infections such as pneumonia, urinary tract infections, skin and skin structure infections and primary or secondary bacteremia which is generally ascribed to the widespread use of antimicrobial agents. In a recent report the Infectious Diseases society of America specifically addressed three categories of MDR- Multi Drug Resistant- gram negative bacilli namely extended spectrum cephalosporin resistant Escherichia coli and Klebsiella spp., MDR Pseudomonas aeruginosa and Carbapenem-resistant Acinetobacter spp.

Moreover, there are now a growing number of reports of

Financial or Other, Competing Interest: None.

Submission 11-12-2015, Peer Review 12-12-2015,

Acceptance 24-12-2015, Published 28-12-2015.

Corresponding Author:

Dr. M. Swarajya Lakshmi,

Associate Professor,

Department of Microbiology,

Maheshwara Medical College and Hospital,

Chitkul Village, Isnapur X Roads,

Medak, Telangana.

E-mail: drswarajya@yahoo.com

DOI:10.14260/jemds/2015/2560 cases of infections caused by gram negative organisms for which no adequate therapeutic options exist. This return to pre-antibiotic era has become a reality in many parts of the world.[2]

So for the prevention of nosocomial infections a thorough knowledge of the infection rates and of the source, type and nature of invading micro-organisms along with risk factors associated with infection is the starting point.[2,3] Also knowledge of the resistivity pattern of different clinical isolates of hospital has been the global necessity for control of emergence of resistance to antimicrobial agents.[3] Furthermore, this screening would provide a valuable and critical data that could help physicians in a way of successful treatment in addition to health care settings policy towards antimicrobial drug programming and invention of new drugs.

Therefore in vitro antimicrobial susceptibility testing has been done by many researchers as a useful method to identify drug resistance pattern of clinical isolates. Characterization of bacteria that are resistant to multiple antimicrobial agents are needed promptly, timely and locally across all healthcare settings within a consistent pattern so that such baseline data could be reliably compared inside and outside the country. ${ }^{[4]}$

\section{AIMS AND OBJECTIVES}

This study is done to investigate the effect of antibiotics over the isolated micro-organisms from various samples in MNR Hospital. 


\section{MATERIALS AND METHODS}

In this prospective study, after Institutional Ethical Committee approval, clinical samples from all infected patients attending MNR Hospital, Fasalwadi received in Microbiology lab over a period of 6 months are considered. Total of 676 clinical samples (Mid-stream urines, blood, sputum, pus swabs, throat swabs, vaginal swabs, aspirated fluids from body cavities, CSF) are included in the study. Samples collected aseptically in sterile containers are labelled in central lab unit of hospital and processed within $30 \mathrm{~min}$ to $1 \mathrm{hr}$ of collection.

\section{Inclusion Criteria}

In this study, only Gram-Negative bacilli were included.

\section{Exclusive Criteria}

Gram Positive bacterial isolates and fungal isolates were excluded.

\section{METHODS}

All the above samples are cultured on Blood agar, and McConkey agar plates and incubated at $37^{\circ} \mathrm{C}$ for $24-48 \mathrm{hrs}$. Isolates were sub-cultured and colonies were screened for Gram Negative (GN) isolates. Identification of isolates was done by Gram staining, Catalase, Oxidase tests, Triple sugar Iron TSI agar test, Citrate utilization, Indole test, Methyl Red [MR], Voges Proskauer [VP], Urease tests. Result interpretation was based on conventional methods described in Mackie McCartney.[5] Antibiotic Susceptibility Testing [AST] done on Mueller Hinton Agar [MHA] with Kirby-Bauer disc diffusion method according to Clinical and Laboratory Standards Institute [CLSI] guidelines.[6] The antibiotic discs used were Ampicillin (10mcg), Piperacillin (100mcg), Cotrimoxazole $(25 \mathrm{mcg})$, Gentamicin $(10 \mathrm{mcg})$, Amikacin

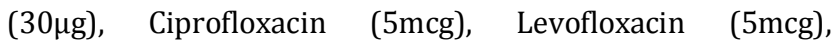

Ceftazidime (30 mcg), Ceftriaxone (30 mcg), Cefoperazone (75mcg), Imipenem $(10 \mu)$, Meropenem (10mcg). All these discs were procured from Hi Media, Mumbai.

\section{RESULTS}

A total of 156 Gram Negative Bacilli (GNB) were isolated from various specimens. Highest isolation rate was observed from pus $(33.5 \%)$, sputum $(27 \%)$, urine $(20.5 \%)$, blood $(12.1 \%)$ and body fluids (4.5\%). Table 1 .

Escherichia coli is the most common isolate (64) followed by Klebsiella (56), Proteus (14), Pseudomonas (13) and Citrobacter (9). Table 2. Antibiotic sensitivity pattern of 12 different antibiotics were done in the study. All the isolates are sensitive to Imipenem and Meropenem (100\%) followed by Levofloxacin. Details in Table 3 and Table 4.

\begin{tabular}{|c|c|c|}
\hline Specimen & No. of Samples & Isolates \\
\hline Urine & 312 & 64 \\
\hline Pus & 209 & 70 \\
\hline Sputum & 55 & 15 \\
\hline Body fluids & 67 & 03 \\
\hline Blood & 33 & 04 \\
\hline Total & $\mathbf{6 7 6}$ & $\mathbf{1 5 6}$ \\
\hline \multicolumn{2}{|c|}{$\begin{array}{r}\text { Table 1: Total number of gram negative } \\
\text { organisms from different specimens }\end{array}$} \\
\hline
\end{tabular}

\begin{tabular}{|c|c|c|}
\hline Bacterial Isolates & No. of Isolates & Percentage \\
\hline Esch. coli & 64 & 41 \\
\hline Klebsiella spp. & 56 & 36 \\
\hline Proteus & 14 & 09 \\
\hline Pseudomonas & 13 & 8.3 \\
\hline Citrobacter & 09 & 5.7 \\
\hline \multicolumn{2}{|c|}{ Table 2: Distribution of Gram negative } \\
bacterial isolates (n=156)
\end{tabular}

\begin{tabular}{|c|c|c|c|c|c|c|}
\hline Antibiotics & & $\begin{array}{l}\text { E. coli } \\
N=64\end{array}$ & $\begin{array}{c}\text { Klebsiella } \\
N=56\end{array}$ & $\begin{array}{c}\text { Proteus } \\
\mathrm{N}=14\end{array}$ & $\begin{array}{c}\text { Pseudomonas } \\
\mathrm{N}=13\end{array}$ & $\begin{array}{c}\text { Citrobacter } \\
\mathrm{N}=09\end{array}$ \\
\hline & $S$ & $5(7.9 \%)$ & $49(87.5 \%)$ & $9(64.3 \%)$ & $5(38.4 \%)$ & $3(33.3 \%)$ \\
\hline Ampicillin & $\mathrm{R}$ & $59(92.1 \%)$ & $7(12.5 \%)$ & $5(35.7 \%)$ & $8(61.5 \%)$ & $6(66.6 \%)$ \\
\hline \multirow[b]{2}{*}{ Piperacillin } & $S$ & $35(54.7 \%)$ & $27(48.2 \%)$ & $12(85.7 \%)$ & $9(69.2 \%)$ & $7(77.7 \%)$ \\
\hline & $\mathrm{R}$ & $29(45.3 \%)$ & $29(51.8 \%)$ & $2(14.3 \%)$ & $4(30.8 \%)$ & $2(22.2 \%)$ \\
\hline \multirow[b]{2}{*}{ Cotrimoxazole } & $S$ & $34(53.2 \%)$ & $19(34 \%)$ & $3(21.5 \%)$ & $6(46.2 \%)$ & $4(44.5 \%)$ \\
\hline & $\mathrm{R}$ & $30(46.8 \%)$ & $37(66 \%)$ & $11(78.5 \%)$ & $7(53.8 \%)$ & $5(55.5 \%)$ \\
\hline \multirow[b]{2}{*}{ Gentamycin } & $\mathrm{S}$ & $52(81.3 \%)$ & $42(75 \%)$ & $9(64.3 \%)$ & $12(92.4 \%)$ & $5(55.5 \%)$ \\
\hline & $\mathrm{R}$ & $12(18.7 \%)$ & $14(25 \%)$ & $5(35.7 \%)$ & $1(7.6 \%)$ & $4(44.5 \%)$ \\
\hline \multirow[b]{2}{*}{ Amikacin } & $\mathrm{S}$ & $60(93.75 \%)$ & $49(87.5 \%)$ & $11(78.6 \%)$ & $13(100 \%)$ & $7(77.7 \%)$ \\
\hline & $\mathrm{R}$ & $4(6.25 \%)$ & 7 (12.5\%) & $3(21.4 \%)$ & $0-0 \%$ & $2(22.2 \%)$ \\
\hline \multirow[b]{2}{*}{ Ciprofloxacin } & $\mathrm{S}$ & $46(72 \%)$ & $50(89.3 \%)$ & $11(78.6 \%)$ & $12(84.6 \%)$ & $5(55.5 \%)$ \\
\hline & $\mathrm{R}$ & $18(28 \%)$ & $6(10.7 \%)$ & $3(21.4 \%)$ & $2(15.4 \%)$ & $4(44.5 \%)$ \\
\hline \multirow[b]{2}{*}{ Levofloxacin } & $S$ & $62(96.9 \%)$ & $53(94.65 \%)$ & $12(85.8 \%)$ & $12(92.3 \%)$ & $8(88.9 \%)$ \\
\hline & $\mathrm{R}$ & $2(3.1 \%)$ & $3(5.35 \%)$ & $2(14.2 \%$ & $1(7.7 \%)$ & $1(11.1 \%)$ \\
\hline \multirow[b]{2}{*}{ Ceftazidime } & $S$ & $34(53.2 \%)$ & $29(51.8 \%)$ & $8(57.2 \%)$ & $10(77.2 \%)$ & $6(66.6 \%)$ \\
\hline & $\mathrm{R}$ & $30(46.8 \%)$ & $27(48.2 \%)$ & $6(42.8 \%)$ & $3(23.7 \%)$ & $3(33.4 \%)$ \\
\hline \multirow[b]{2}{*}{ Ceftriaxone } & $S$ & $34(53.2 \%)$ & $38(67.9 \%)$ & $10(71.5 \%)$ & $10(77 \%)$ & $5(55.5 \%)$ \\
\hline & $\mathrm{R}$ & $30(46.8 \%)$ & $18(32.1 \%)$ & $4(28.5 \%)$ & $3(23 \%)$ & $4(44.5 \%)$ \\
\hline \multirow[b]{2}{*}{ Cefoperazone } & $\mathrm{S}$ & 37 (57.8\%)- & $34(60.7 \%)$ & $9(64.3 \%)$ & $0-0$ & $6(66.6 \%)$ \\
\hline & $\mathrm{R}$ & $27(42.2 \%)$ & $22(39.3 \%)$ & $5(35.7 \%)$ & $13(100 \%)$ & $3(33.4 \%)$ \\
\hline \multirow[t]{2}{*}{ Imipenem } & $\mathrm{S}$ & $64(100 \%) 9$ & $56(100 \%)$ & $14(100 \%)$ & $13(100 \%)$ & $9(100 \%)$ \\
\hline & $\mathrm{R}$ & R $0-0$ & $0-0$ & $0-0$ & $0-0$ & $0-0$ \\
\hline \multirow[b]{2}{*}{ Meropenem } & $\mathrm{S}$ & $64(100 \%)$ & $56(100 \%)$ & $14(100 \%)$ & $13(100 \%)$ & $9(100 \%)$ \\
\hline & $\mathrm{R}$ & $0-0$ & $0-0$ & $0-0$ & $0-0$ & $0-0$ \\
\hline & & & & & & \\
\hline
\end{tabular}




\begin{tabular}{|c|c|c|}
\hline Antibiotic (mcg) & Sensitivity (n=156) & Resistance \\
\hline Ampicillin & $35(22.4 \%)$ & $131(84 \%)$ \\
\hline Piperacillin & $90(57.7 \%)$ & $66(42.3 \%)$ \\
\hline Cotrimoxazole & $66(42.3 \%)$ & $90(57.7 \%)$ \\
\hline Gentamycin & $120(76.9 \%)$ & $36(23.1 \%)$ \\
\hline Amikacin & $140(89.7 \%)$ & $16(10.3 \%)$ \\
\hline Ciprofloxacin & $123(79 \%)$ & $33(21 \%)$ \\
\hline Levofloxacin & $147(94.2 \%)$ & $9(5.8 \%)$ \\
\hline Ceftazidime & $87(55.8 \%)$ & $69(44.2 \%)$ \\
\hline Ceftriaxone & $97(62.2 \%)$ & $59(37.8 \%)$ \\
\hline Cefoperazone & $86(55 \%)$ & $70(45 \%)$ \\
\hline Imipenem & $156(100 \%)$ & $0(0 \%)$ \\
\hline Meropenem & $156(100 \%)$ & $0(0 \%)$ \\
\hline \multicolumn{2}{|c|}{ Table 4: Overall resistance to antibiotics } \\
\hline
\end{tabular}

\section{DISCUSSION}

Antibiotics when first introduced were considered as a magic bullet. A single injection of penicillin could eradicate a lifethreatening infection. Unfortunately with time due to malpractices or natural causes, most of the cheaper antibiotics have lost their efficacy and more and more expensive and complicated antibiotics were introduced and marketed to combat simple infection. The microbial pathogens as well as their antibiotic sensitivity pattern, may change from time to time and place to place.[7] Out of 156 Gram Negative bacterial isolates in our study, Escherichia coli is the most common isolate followed by Klebsiella spp. similar to other studies. ${ }^{[4,8,9]}$ Most of these isolates are highly resistant to commonly used antibiotics like ampicillin (84\%), which correlated closely with other studies.[2,8]

High sensitivity was noted to Amikacin (89\%) and Gentamycin $(77 \%)$ in our study, which is in tandem with the work done by other authors. ${ }^{[3,4,9]}$ Also Pseudomonas showed $100 \%$ sensitivity to Amikacin in our study. All isolates (100\%) were susceptible to Imipenem and Meropenem.[9,10] A 44.23\% were resistant to ceftazidime, $37.8 \%$ were resistant to ceftriaxone, $44.87 \%$ were resistant to cefoperazone correlated well with other studies.[1,10] whereas $70-75 \%$ resistance to cephalosporins was reported by author in 9 . Sensitivity to cotrimoxazole (42\%) in our work closely correlates with the work of authors Kala Yadav and Raminder Sandhu.[11,12] Quinolones were highly effective in our study. Only $21.15 \%$ isolates were resistant to ciprofloxacin and $5.8 \%$ isolates were resistant to levofloxacin. Similar to the work done by Patel Bhaumik.[1]

Contrast to our work are studies, which reported higher drug resistance to quinolones.[2,11] aminoglycosides, cephalosporins.[13,14] Such variations in the antimicrobial sensitivity pattern among different studies may be due to the variations in duration and dose of the antibiotics used, spectrum of antibiotics used and differing antibiotic policies among different hospitals.[3]

\section{Limitations of the Study}

This study can be further extended by testing for Extended Spectrum Beta Lactamases (ESBLs) and Metallo-BetaLactamases (MBLs).

\section{CONCLUSION}

This study provides the current trend of drug resistant GNB among clinical samples, so as to keep track of the resistivity that may arise in future and most important to know the massive use of particular antibiotics and also their misuse, so that measures could be taken to prevent severe consequences.

To conclude, antibiotic resistance in our area is still moderate with good sensitivity to Amikacin, Gentamycin, Quinolones and Carbapenems. So it is essential to test for older generation antibiotics before deciding on higher antibiotics, which will have a tremendous impact on the treatment as well as cost effectiveness. It is recommended that an updated unitspecific antibiograms should be done and provided to clinicians at least once in a year to ensure that the data are current and useful. So that it is of help to them to devise empiric regimens that have a greater likelihood of covering the organisms posing risk and at the same time reduce the unnecessary administration of broad spectrum antibiotics.

\section{ACKNOWLEDGEMENT}

Mr. M. Ravi Varma, Vice Chairman; Dr. V. Satya Prasad, Professor, Department of Anatomy; Dr. G. Shobha Paul, Professor and HOD, Department of Microbiology, MNR Medical College and Hospital for giving us the opportunity and timely guidance.

\section{REFERENCES}

1. Patel Bhaumik V, Patel Purav G, Raval Payal N, et al. Bacteriological profile and antibiogram of gram negative organisms isolated from Medical and Neurology Intensive Care Unit with special reference to multi-drug resistant organisms. Nat J Med Res 2012;2(3):335-38.

2. Binit Lamichhane, Chandan Thakur, Jain SK. Antibiotic resistance patterns of gram negative isolates in a Tertiary Care Hospital of Nepal. Asian J Pharm Clin Res 2014;7(3):30-33.

3. Kritu Panta, Prakash Ghimire, Shiba Kumar Rai, et al. Antibiogram typing of gram negative isolates in different clinical samples of a Tertiary Hospital. Asian J Pharm Clin Res. 2013;6(1):153-56.

4. Seyedah Afrooz Azmil, Shahram Boroumandi, Mohammad Rahbar. Prevalence of drug resistance pattern in admitted patients to Pars Hospital, Tehran, Iran. IJBSCI 2014;2(1):14-21.

5. Colle, Fraser, Marmion, et al. Practical Medical Microbiology, 14th edition, 2006.

6. Clinical and Laboratory Standards Institute (CLSI). Analysis and presentation of cumulative antimicrobial susceptibility test data. 3rd ed. Approved guidelines M39A3. Wayne PA. CLSI, 2009.

7. Shamim Mumtaz, Naeem Aktar, Abbas Yayat. Antibiogram of aerobic pyogenic isolates from wounds and abscesses of patients at Rawalpindi. Pakistan J Med Res 2002;41:1.

8. Chikere CB, Chikere BO, Omani VT. Antibiogram of clinical isolates from a hospital in Nigeria. Afr J Biotechnol 2008;7(24):4359-63.

9. Jaya Sankarankutty, Soumya Kaup. Distribution and antibiogram of gram negative isolates from various clinical samples at a Teaching Hospital, Tumkur. Sch J App Med Sci 2014;2(3):927-31.

10. Iraj Alipourfard, Nilufar Yeasam in Nili. Antibiogram of extended spectrum beta-lactamase producing Escherichia coli and Klebsiella pneumoniae isolated from hospital sample. Bangladesh J Med Microbiol 2010;4(1):32-36. 
11. Kala Yadav ML, Ashmita Raja. Bacteriological profile and antibiogram of Gram negative clinical isolates from a Tertiary Care Centre. Int J Res Health Sci 2014;2(3):734-9.

12. Raminder Sandhu, Hema Prakash, Nagdawane RP. Aerobic bacterial isolates in suppurative infections and their antibiograms-A reflection of infection control. www.ijpbsonline.com 2014;4(2):186-92.
13. Mohammadi-Mehr M, Feizabadi MM. Antimicrobial resistance pattern of Gram negative bacilli isolated from patients at ICUs of Army Hospitals in Iran. Iran J Microbiol 2011;(1):26-30.

14. Gunserena, Mamikoglua L, Ozturkb S, et al. A surveillance study of antimicrobial resistance of Gram negative bacilli isolated from patients at Intensive Care Units in eight hospitals in Turkey. J Antimicrib Chemother 1999;43(3):373-78. 